\title{
Valor do indice uncinarico em identificações medico legaes
}

\author{
DR. WILSON G. SMILLIE \\ Director do Instituto de Hygiene, Faculdade de Medicina @ Cirurgia. São Paulo - Brasil
}

Estimulado por uma observação casual de meu illustre collega o Prof. de Medicina Legal, Dr. Oscar Freire, veio-me a idea de que a formula uncinarica, isto é, o numero e especie de uncinarias abrigadas por um individuo pudesse ser indice de algum valor em certos casos de identificação medico legal. Não é que factor tão variavel, como a infestação uncinarica, possa fornecer indice exacto por meio đo qual possamos identificar os individuos, mas pareceu-me que a formula parasitaria possa talvez dar indicações, que, conjugadas a varios outros dados auxiliem a deslindar factos importantes para orientação da Justiça.

A idea de usar a formula parasitaria para identificações medico legaes, apesar de pouco usada, não nos é propria.

Em 1899, em Lyon, uma velha foi encontrada assassinada e, no leito da victima, excrementos attestavam que o criminoso tinha ajuntado a seu crime uma immunda porcaria. O Dr. Lacassagnee descobriu nestes excrementos uma grande quantidade de oxyuris rermiculares e, examinando as fezes de oito pessoas que se tinham tornado suspeitas, achou oxyuris em uma dellas; esta prova reunida a outras que haviam sido colligidas no inquerito, forçou o assassino a confessar o seu crime. (1)

E' interessante notar nesse respeito que ao norte da Allemanha, diz Groos, os assassinos creem que não serão descobertos se deixarem seus excrementos no local do crime.

Em minhas investigações no tocante á infestação uncinarica no Brasil, tive occasião de notar na uncinariose a existencia de certas regras geraes de notavel constancia.

Obtive meus dados pela contagem das uncinarias de mais de 1000 individuos no Brasil. Escolhi para minhas investigações individuos em todas as condições sociaes, provenientes de quasi todos os esta-

(1) Lacassagne - Alfredo Niceforo - La police et l'enquête juনiciarie scientifique. Paris, 1907 - pg. 233-234. 
dog da União, incluindo todas as edades, varias raças, ambos os sexos, officios varios, etc.

Em todos os casos registei cuidadosamente o nome, a edade, o sexo, a percentagem da hemoglobina, a profissão nos ultimos dez annos, a occupação actual, se andavam calçados ou não, e si o doente já tomara anteriormente algum anthelmintico. A s $_{\text {s }}$ uncinarias eram expellidas por uma boa dose de chenopodio que faz eliminar $99 \%$ dos parasitas e as fezes todas eram recolhidas durante 48 horas, os vermes classificados e contados. Os pormenores do methodo seguido foram descriptos (2) em artigo já publicado.

O processo de classificação das uncinarias é muito simples; separam-se os machos des femeas, e os necatores dos ancylostomos. Cerca de mil uncinarias podem ser contadas e classificadas em poucos minutos. As uncinarias não se desprendem rapidamente nos intestinos do seu hospede após a morte, de sorte que esta classificação pode ser feita alguns dias depois da morte do individuo.

Os resultados das minhas pesquizas sobre Ancylostomose no Brasil já foram publicados (3). Certos factos geraes referentes á uncinariose no Brasil tornaram-se bem patentes e podem ser enunciados sob a forma de proposições. Escolhi as de maior interesse para a medicina legal e consideral-as-ei sob tres pontos de vista:

A) O gráo da infestação uncinarica no individuo.

B) A proporção relativa de Ancylostoma duodenale para o Necator Americanus.

C) A proporção relativa entre necatores machos e femeas, abrigadas por individuo.

\section{A) O gráo da infestação uncinarica no individuo}

A uncinariose se adquire pelo contacto directo persistente e demorado da pelle com o solo muito polluido. Em egualdade de outros factores pode-se dizer que o gráo da infestação está na proporção directa do numero de horas que o individuo gasta por dia trabalhando descalço na roça. Portanto:

\section{Proposição n. ${ }^{a} 1$.}

Os moradores de cidades, que viveram durante annos em communidades saneadas, onde ha exgottos e latrinas, soffrem apenas de infestação accidental, de pouca importancia e abrigam ao maximo 5-10 uncinarias.

\section{Proposição n.' 2.}

Os moradores de villas, que não trabalham na roça tae $e_{S}$ como: donos de lojas, barbeiros, funccionarios publicos, professores, donos de hotel, negociantes e suas familias, soffrem de infestação insignificante, ainda quando a villa goza de poucas commodidades sanitarias ou não as tem de todo, e a zona circumvisinha está gravemen-

(2) Darling S. T. and Smillie W. G. - Hookworm Studies in Brasil - Monographe of Rockefeller Institute - 14.

(3) Smillie W. G. - Existencia e disseminaçāo do Ancylostoma Duoc.cnale no Brasil - Boletim do Instito de Hygiene - N.o 7. 
te polluida. Nestes individuos a média é de 30-40 uncinarias por pessoa.

Proposiç:ão n.' :

Os moradcres de fazendas que não trabalham na roça, administradores, fiscaes, machinistas, etc., não soffrem de infestação grave ainda quando esta se observa entre todos os outros empregados da fazenda. Em media geral os administradores e fiscaes abrigam menos de 20 uncinarias por pessoa.

Proposição n.* 4.

Os individuos occupados em serviços pastoris, por exemplo, moradores de certas zonas em Minas, Matto Grosso e no Paraná, não soffrem de infestação grave, pois não trabalham na roça. E' raro encontrar-se casos com mais de 50 uncinarias.

\section{Proposição n.* 5}

Os trabalhadores de roça soffrem de infestação grave, em media mais de 200 uncinarias por pessoa. Os homens abrigam mais uncinarias que os meninos, estes mais do que as mulheres, e estas mais do que as meninas. Ha uma excepção a esta regra: é a dos individuos que usam sapatos emquanto trabalham na roça. Estes casos são raros.

Estas regras não são infalliveis, são entretanto de notavel constancia. Consideraremos a applicação das mesmas ás identificações medico legaes quando tratarmos das outras proposições.

\section{B) Proporção relativa entre o Necator Americanus e o Ancylostoma Duodenale.}

Descrevi num artigo anterior a historia da disseminação dessas duas especies de uncinarias no Brasil. Pode-se dizer em resumo que o Necator Americanus foi provavelmente introduzido pelos escravos que o disseminaram por quasi todo o Brasil.

o Ancylostoma Duodenale pode ter sido introduzido pelos primeiros immigrantes vindns do $\approx$ ul da Europa mas sua distribuição não foi muito extensa. Esta uncinaria se encontra principalmente entre colonos italianos e seus descendentes e visinhos, nas fazendas de café do Estado de São Paulo; em trabalhadores nas chacaras

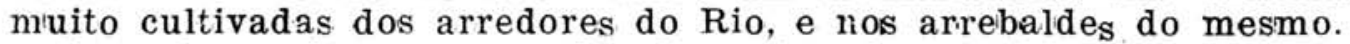

Os colonos japonezes estão disseminando rapidamente ovos de Ancylostoma Duodenale, por muitas partes do territorio do Estado de São Paulo.

No tocante á proporção relativa entre o Ancylostoma Duodenale e o Necator Americanus no Brasil notamos o seguinte:

\section{Proposição n.' 1}

Os brasileiros nativos que vivem no interior, em districtos afastados, longe do contacto com immigrantes estrangeiros, soffrem de infestação quasi que exclusivamente pelo Necator Americanus. A sua 
infestação pelo Ancylostoma Duodenale não attinge a $1 \%$ do numero total de uncinarias abrigadas.

\section{Proposição n. ${ }^{\circ} \mathbf{2}$}

Os colonos italianos e espanhóes e seus descendentes nas fazendes de café do Estado de São Paulo abrigam uma proporção relatîvamente alta do Ancylostoma Duodenale ou seja $8-10 \%$ da infestação uncinarica total.

\section{Proposição n.* 3}

Os brasileiros que trabalham nas mesmas roças onde existem colonos estrangeiros rapidamente adquirem a formula uncinarica de seus vizinhos. Os brasileiros, trabalhando na mesma, ou em fazenda vizinha, onde não entrem em contacto com estrangeiros conservam sua forma uncinarica brasileira, isto é $1-2 \%$.

\section{Proposição n.* 4}

Os colcnos japonezes com menos de 2 annos de residencia no Brasil abrigam quasi que exclusivamente o Ancylostoma Duodenale.

\section{Proposição n." 5}

Os japonezes, italianos e brasileiros que trabalham juntos nas mesmas roças soffrem modificação reciproca de sua formula uncinarica de sorte que ao cabo de 4 a 5 annos a formula é identica para todos.

\section{Proposição n. ${ }^{a} 6$}

ns trabalhadores de chacaras nos suburbios do Rio, portuguezes e brasileiros, abrigam proporção relativamente alta do Ancylostoma Duodenale ou seja $5 \%$ da infestação uncinarica total.

\section{C) Proporção relativa de Necatores machos e femeas}

Ha outro facto interessante sob o ponto de vista medico legal: é a proporção relativa de necatores machos e femeas abrigados por certo individuo.

\section{Proposição n.* 1.}

Um individuo vivendo em condições em que está continuamente exposto á reinfecção abrigará um numero quasi igual de machos e femeas. Os machos são, um pouco mais numerosos, constando a proporção de 100 femeas para 100 machos. Esta ${ }_{1}$ observação se baseia na contagem de mais de 50.000 uncinarias.

\section{Proposição n.' 2}

Quando un individuo não está mais exposto á adquirir uncinarias, estas vão gradualmente morrendo mas as femeas são mais resistentes do que os machos, de sorte que ao cabo de uns 3 a 4 
annos, sua formula uncinarica constará aproximadamente de 100 femeas para 70 machos.

\section{Exemplos typicos}

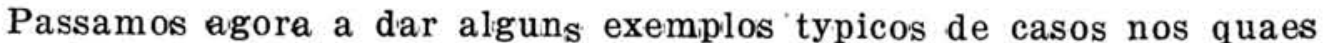
os principios geraes que espuzemos junto com outros varios dados que já tenho publicado, ou são bem conhecidos, poderão auxiliar a indentificação medico legal.

\section{Caso n." 1}

Encontrou-se perto da linha da estrada de ferro, nas visinhanças da cidade de São Paulo, um cadaver. O obito fôra evidentemente musado pela passagem do trem, e o individuo não pudera ser indentificado. Na necroscopia observou-se que este individuo abrigava 338 uncinarias. A contagem differencial deu os seguintes resultados:

$\begin{array}{lr}\text { Ancylostoma } & \text { femeas, } 10 ; \text { machos, } 18 . \\ \text { Necator } & \text { femeas, } 110 ; \text { machos, } 148 .\end{array}$

Destes dados podemos immediatamente concluir com muita probabilidade de acerto que o indiviảuo em questão tinha entre 15 e 45 annos, era brasileiro ou estrangeiro, residente ha muitos annos no Brasil.

Devia ter vivido no estado do Rio ou no de São Paulo, labutando sempre e ainda recentemente, como trabelhador de enxada.

E' incontestavel que estas informações combinadas com outros dados obtidos deveriam auxiliar a identificação do morto.

Caso n. ${ }^{0} 2$

Prenderam em Lençóes, Estado da Bahia um camarada bahiano, accusado de ter morto um colono dous annos antes. $O$ crimie se dera em São Carlos, Estado de São Paulo numa fazenda de café. o bahiano declarou entretanto ter vivido sempre nas visinhanças de Lençóes e nunca ter estado no Estado de São Paulo.

Administrou-se a este individuo o tratamento padrão pelo chenopodio; suas fezes foram recolhidas e as uncinarias contadas.

Os resultados foram os seguintes:
Ancylostoma
femeas, $12 ;$ machos, 7 . Necator
femeas, 188; machos, 126 .

Estes dados demonstraram que provavelmente o indiciado mentiu, pois com toda probabilidade trabalhou em São Paulo em alguma fazenda, onde esteve em contacto com colonos italianos ou japonezes, e isto nos ultimos tres annos.

Caso n.' 3.

Encontrou-se o cadaver de um homem, apparentemente ainda jovem, de trajes modestos á beira da estrada numa villa do interior. A necroscopia revelou entre outros factos, que elie não abrigava uncinaria alguima. 
Este facto basta para demonstrar que o individuo em questão morara na cidade, ou pelo menos, não vivera no interior durante os ultimos 4 a 5 annos. Elle poderia ter vivido em alguma fazenda ou villa onde se dedicasse a uma profissão em que não estivesse expostc a adquirir a infestação, como na de barbeiro, de machinista, etc., entretanto neste caso elle provavelmente abrigaria umas 10 a 30 uncinarias. E' muito mais provavel que elle fosse da cidade, recem chegado ao Interior.

Caso n.' 4

Deu entrada na Santa Casa de São Paulo um japonez moribundo, coffrendo de malaria maligna, vindo elle a fallecer no dia seguinte. O doente viera do interior e não tinha parentes ou amigos. A necroscopia revelou o seguinte:
Ancylostioma
femeas, 32 ; machos, 38 .
Necator
femeas, $36 ;$ machos, 52 .

E' evidente que este homem emmigrara ha pouco, e que residira no Brasil provavelmente menos de dous annos.

Ha duas profissões preferidas pelos japonezes, a de "chauffeur" e a de colono. Este individuo escolhera provavelmente a segunda dellas. Caso elle tivesse residido no Brasil uns 4 a 5 annos, sua formula uncinarica deveria incluir muito mais necatores e menos ancylostomos. Elle sem duvida trabalhara na roça pois já adquirira um certo numero de necatores.

\section{Caso n." 5}

Encoutrou-se no rio um cadaver, evidentemente o de um individuo que se afogara. O cabello cortado á escovinha suggeria a possibilidade de ter elle recentemente sahido da prisão.

A formula uncinarica foi a seguinte:

$\begin{array}{ll}\text { Ancylostoma } & \text { femeas, } 0 ; \text { machos, } \\ \text { Necator } & \text { femeas, } 128 ; \text { machos, } 75 .\end{array}$

Estes resultados lembram a probabilidade de ter este individuo vivido no interior, inteiramente afastado de immigrantes (ausencia de ancylostomos). Sendo o numero de nectares elevado e as femeas muito mais numerosas que os machos, é provavel ter esse homem vivido anteriormente na roça, mas viver recentemente em localidade onde não havia opportunidade de estar sendo infestado. Provavelmente passara em sua nova residencia, alguma instituição, talvez a prisão, pelo menos dous ou tres annos.

Estas informações são suggestivas quanto á proveniencia do morto.

Estes poucos casos si bem que inteiramente ficticios, criados pela necessidade de exemplificar, são, não sómiente perfeitamente possiveis, como ainda podem ser observados frequentemente.

$A_{S}$ conclusões que delles tiramos não são apenas fructo da imaginação, mas decorrem da applicação das proposições que enunciei.

O assumpto é interessantissimo, estimula a imaginação, e facil 
seria o cahirmos em engano se nos deixassemos guiar exclusivamente pela imaginação, sem nos limitarmos á applicação de factos provados ou procurarmos applicar regras de alcance geral a factos especificos.

Para provar o valor do methodo será preciso fazer a contagem dos vermes em grande numero de cadaveres, sobre cujos antecedentes se tenha noticia exacta.

Prsentemente estou fazendo a contagem das uncinarias nos cadaveres cuja necroscopia é feita na Faculdade de Medicina. Depois de interpretados os resultados pedirei á Sta. Casa a historia dos finados afim de comparar os factos com a theoria. Só depois de observar uns 200 a 500 casos é que poderei formar conclusões exactas quanto ao valor do indice uncinarico em identificações medico legaes. 